\title{
Retroperitoneal Extrapleural Approach for Corpectomy of the First Lumbar Vertebra : Technique and Outcome
}

Ihab Zidan, M.D., Wael Khedr, M.D., Ahmed Abdelaziz Fayed, M.D., Ahmed Farhoud, M.D.

Department of Neurosurgery, Faculty of Medicine, Alexandria University, Alexandria, Egypt

Objective : Corpectomy of the first lumbar vertebra (L1) for the management of different L1 pathologies can be performed using either an anterior or posterior approach. The aim of this study was to evaluate the usefulness of a retroperitoneal extrapleural approach through the twelfth rib for performing L1 corpectomy.

Methods : Thirty consecutive patients underwent L1 corpectomy between 2010 and 2016. The retroperitoneal extrapleural approach through the 12th rib was used in all cases to perform single-stage anterior L1 corpectomy, reconstruction and anterior instrumentation, except for in two recurrent cases in which posterior fixation was added. Visual analogue scale (VAS) was used for pain intensity measurement and ASIA impairment scale for neurological assessment. The mean follow-up period was 14.5 months.

Results : The sample included 18 males and 12 females, and the mean age was 40.3 years. Twenty patients (67\%) had sensory or motor deficits before the surgery. The pathologies encountered included traumatic fracture in 12 cases, osteoporotic fracture in four cases, tumor in eight cases and spinal infection in the remaining six cases. The surgeries were performed from the left side, except in two cases. There was significant improvement of back pain and radicular pain as recorded by VAS. One patient exhibited postoperative neurological deterioration due to bone graft dislodgement. All patients with deficits at least partially improved after the surgery. During the follow-up, no hardware failures or losses of correction were detected.

Conclusion : The retroperitoneal extrapleural approach through the 12th rib is a feasible approach for L1 corpectomy that can combine adequate decompression of the dural sac with effective biomechanical restoration of the compromised anterior loadbearing column. It is associated with less pulmonary complication, no need for chest tube, no abdominal distention and rapid recovery compared with other approaches.

Key Words : Spine · Lumbar vertebrae · Spinal fusion.

\section{INTRODUCTION}

Corpectomy of the first lumbar vertebra (L1) is indicated in the surgical treatment of traumatic unstable burst fractures, vertebral osteomyelitis, vertebral tumors and spinal deformi- ties $^{10,12,20,29,32,33,43)}$. This region of the spine is challenging to access surgically due to the presence of the diaphragm at the thoraco-lumbar junction ${ }^{6}$. L1 corpectomy can be performed using either an anterior or posterior approach. Although most surgeons are familiar with this procedure, posterior transpe-

- Received : October 17, 2017 •Revised : January 7, 2018 •Accepted : March 21, 2018

- Address for reprints : Ihab Zidan, M.D.

Department of Neurosurgery, Faculty of Medicine, Alexandria University, 15 Mohamed Masoud St., Wabour elmiah, Alexandria 21526, Egypt Tel : +20-01223558137, Fax : +20-034873076, E-mail : zidanihab@yahoo.fr

This is an Open Access article distributed under the terms of the Creative Commons Attribution Non-Commercial License (http://creativecommons.org/licenses/by-nc/4.0) which permits unrestricted non-commercial use, distribution, and reproduction in any medium, provided the original work is properly cited. 
dicular corpectomy through laminectomy offers limited anterior visualization and is associated with the risks of increasing the pre-existing instability and later loss of correction ${ }^{11,39,47)}$. The recent development of rigid corpectomy reconstruction cages has increased the attractiveness of the anterior approaches to the lumbar and thoracolumbar spine by improving the biomechanical strength of the anterior column support ${ }^{36)}$. Using an anterior approach, L1 corpectomy and decompression of the dural sac with biomechanical restoration of the compromised anterior load-bearing column and anterior instrumentation of the thoracolumbar spine can be simultaneously achieved $^{34)}$. The retroperitoneal extrapleural approach through the twelfth rib allows for the exposure of the lower part of the thoracolumbar junction. This approach has the advantage of reducing the manipulation of the nervous structures and increasing the ability to excise the vertebral body and disc, which consequently increases the ability to place larger interbody fusion devices that have greater rates of fusion $^{12,49)}$. The extrapleural approach can obviate the need for chest tube placement, which decreases morbidity due to pulmonary complications ${ }^{2,12,17)}$. The aim of this study was to evaluate the usefulness, advantages and potential complications of the retroperitoneal extrapleural approach through the twelfth rib for performing $\mathrm{L} 1$ corpectomy for the management of different lumbar pathologies.

\section{MATERIALS AND METHODS}

Thirty consecutive patients with various spinal pathologies were operated on between June 2010 and May 2016 using the retroperitoneal extrapleural approach through the 12 th rib. All procedures performed in the present study were approved by the Ethical Committee of Alexandria University Hospital and were in accordance with the ethical standards of the institutional and/or national research committee and with the 1964 Helsinki declaration and its later amendments or comparable ethical standards. Visual analogue scale (VAS) was used for pain intensity measurement and ASIA impairment scale for neurological assessment. The preoperative evaluations included plain X-rays, computed tomography (CT) and magnetic resonance imaging (MRI) examinations in all cases. A left-sided approach was used in all cases, except for in two cases in which a right-sided approach was used because the pathologies mainly involved the right sides of the vertebrae. Autologous bone grafts from the iliac crest, bone cement and cages were used for the vertebral replacement.

\section{Surgical technique ${ }^{13)}$}

After the induction of general anesthesia, each patient was placed in the lateral decubitus position with the left side up. We preferred to break the operating table in a fashion that increased the distance between the iliac crest and the costal margin. A skin incision was performed along the 12th rib starting 4-8 cm posterior of the midline and extending approximately $10-12 \mathrm{~cm}$ anteriorly. The muscle layers were divided using electrocautery to reach the surface of the 12th rib; then, the periosteum was incised and circumferentially separated from the rib, and the rib was cut at the costotransverse junction. The rib was carefully removed from its bed after splitting the structures attached to its tip, which consisted of the diaphragm superiorly and the transversus abdominus muscle and transversalis fascia inferiorly. The pleura were always protected during this step. The crus of the diaphragm was subsequently disinserted from its spinal attachment and elevated in the cephalad direction with a periosteal elevator. After the elevation of the diaphragm and the retraction of the psoas muscle laterally and inferiorly, the T12-L1 disc was exposed. Careful blunt dissection of the peritoneum was performed from the inner surface of the abdominal wall, and the peritoneum was retracted anteriorly to widen the exposure of the retroperitoneal space. The spine was palpated to identify the soft prominent disc space, and a needle was inserted for an X-ray confirmation of the level. After adequate exposure of the L1 vertebral body with its proximal and distal disc spaces, the segmental vessels at this level were ligated and divided. The disc spaces above and below the corpectomy level were removed, and the endplates of all cartilage were cleared while preserving the cortical parts of the endplates. In cases of traumatic fracture, a subtotal corpectomy of the fractured vertebral body was performed, and the contralateral and anterior vertebral body walls were left in place. In the presence of spinal canal compromise, the posterior wall was also removed to decompress the dura. In the tumor cases, the corpectomy was performed as completely as possible. Different methods were used for the vertebral body reconstruction in this series, including iliac bone graft, bone cement, titanium mesh and titanium cages. After adequate reconstruction, anterior plating 
using Z Plate ATL and Vantage Anterior Fixation System (Medtronic/Sofamor Danek, Memphis, TN, USA) was performed from the last dorsal vertebra (T12) down to the 2nd lumbar vertebra (L2). The lower half of the T12 vertebra could easily be reached without pleural entry in a manner sufficient to place the screws using this approach, but this was not the case for the T12 corpectomy. Before closure, a suction drain was inserted over the corpectomy, and the closure of the rib bed and separate closures of the different layers were performed. A chest tube was inserted only in cases of accidental pleural entrance in which direct repair was not possible. Strong narcotics were given routinely after surgery to decrease the postoperative pain. The patients were usually mobilized on the second postoperative day. No brace was given. The retroperitoneal suction drains were removed 24-48 hours after the surgery. Patients were evaluated regularly immediate postoperative and then every six months both clinically and radiologically. Plain X-ray films (anteroposterior [AP] and lateral views) and CT scan were used for radiological assessment in all our patients. Spinal MRI was performed if any neurological deficit appears or if the back pain increases in severity during the follow up. The mean follow-up period was 14.5 months (range, 10-69 months).

\section{Statistical analysis of the data}

Data were analyzed using IBM SPSS software package version 20.0 (IBM SPSS Inc., Chicago, IL, USA). Qualitative data were described using number and percent. Quantitative data were described using range, mean, standard deviation and median. For ordinal data to compare between the different periods, Wilcoxon signed ranks test was applied. Significance of the obtained results was judged at the $5 \%$ level.

\section{RESULTS}

Thirty consecutive cases were operated on for lesions involving the first lumbar vertebra with their results shown in Table 1. These cases included 18 males and 12 females aged between 18 and 65 years, and the mean age was 40.3 years. All patients presented with back pain, which was the only presentation in 10 cases. In the remaining 20 cases (66.7\%), sensory and/or motor deficits were also reported. The ASIA impairment scale scores of all patients are presented in Table 1. The pathologies encountered in this series included traumatic fracture in 12 cases, osteoporotic fracture in four cases, tumor in eight cases, and spinal infection in the remaining six cases. The surgeries were performed from the left side in all cases, except for two cases in which the pathology mainly involved the right side; therefore, right-sided approaches were utilized in these two cases. We used an iliac bone graft for the vertebral replacement in eight cases (Fig. 1), a titanium mesh in eight cases (Fig. 2), and titanium cages in two cases. In the remaining 12 cases, vertebral reconstruction was performed using bone cement, and these cases all involved vertebral tumors or osteoporotic fractures (Fig. 3). The mean operation time was 220 minutes (range, 160-280), and the mean blood loss volume was $600 \mathrm{~mL}$ (range, 400-1400). Single-stage anterior corpectomy with D12-L2 anterior fixation using an anterior plating system was performed in 28 cases. All these cases

Table 1. Distribution of studied patients according to demographic data, perioperative data and results

\begin{tabular}{lc}
\hline Variable & Value \\
\hline Age (years) & $40.3(18-65)$ \\
Gender & $12(40)$ \\
Female & $18(60)$ \\
Male & \\
Etiology & $12(40)$ \\
Traumatic fractures & $4(13)$ \\
Osteoporotic fractures & $8(27)$ \\
Tumors & $6(20)$ \\
Infection & \\
Surgical site & $28(93)$ \\
Left & $2(7)$ \\
Right & \\
\hline Type of graft & $8(27)$ \\
Iliac bone & $8(27)$ \\
Titanium mesh & $2(6)$ \\
Titanium cage & $12(40)$ \\
Bone cement & $220(160-280)$ \\
Operation time (minutes) & $600(400-1400)$ \\
Blood loss (mL) & $16 / 18(90)$ \\
\hline Fusion rate & \\
\hline Cobb angle $\left({ }^{\circ}\right)$ & \\
Preoperative & \\
\hline Vostoperative & $(2-22)$ \\
\hline
\end{tabular}

Values are presented as mean (range) or number (\%) 

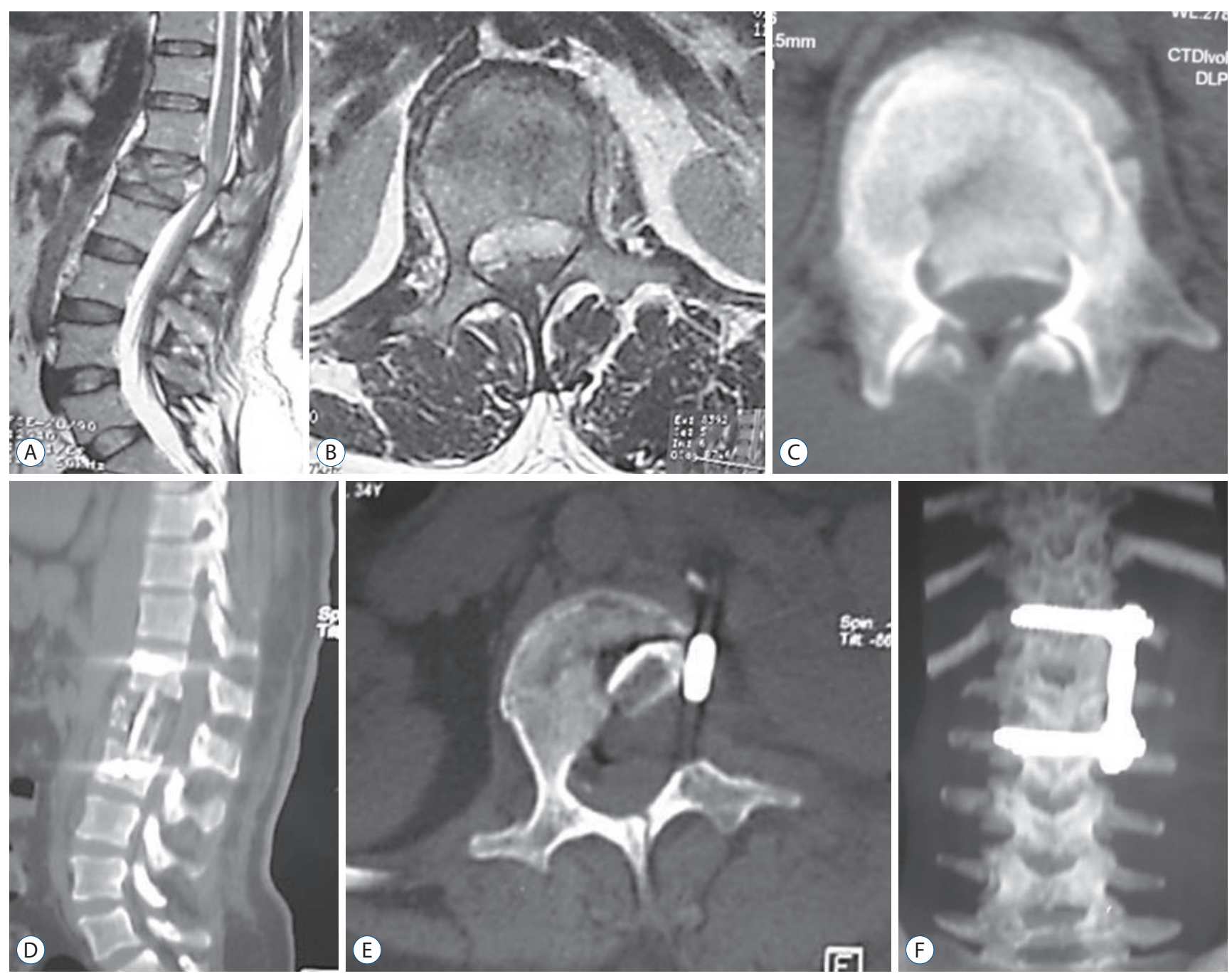

Fig. 1. A and B : Magnetic resonance imaging (sagittal and axial views) showing a traumatic L1 fracture with evident spinal canal compression. C : CT scan (axial view) of the same patient showing a bony fragment inside the spinal canal. D and E : Postoperative follow-up CT scan (sagittal and axial views) showing an L1 corpectomy with vertebral reconstruction using an iliac bone graft with evident spinal canal decompression. F : Postoperative follow-up CT scan with $3 \mathrm{D}$ reconstruction (AP view) showing spinal instrumentation using an anterolateral plate extending from D12 to L2. CT : computed tomography, AP : anteroposterior.

showed an absence of posterior column insufficiency. The remaining two patients had undergone previous surgeries for posterior laminectomy elsewhere; therefore, posterior long segment fixation (two levels above and two levels below) was performed first, followed by anterior corpectomy and vertebral replacement in the same session without anterior plating.

\section{Complications}

Intraoperative complications occurred in six cases, including peritoneal tears in three cases and a pleural tear, a dural tear and excessive blood loss in one case each. The peritoneal and pleural tears were repaired during the surgery without any secondary consequences, whereas the dural tear was sealed using gel foam, and no postoperative cerebrospinal fluid leakage was observed. The excessive blood loss was present in the case with a vertebral hemangioma, and the patient received an intraoperative blood transfusion with a favorable outcome. Postoperative complications were reported in seven patients. Four cases experienced wound infection, and three of these cases were treated conservatively. The fourth case required surgical debridement. Two patients exhibited a painful postoperative scar and received a local steroid injection that elicited a marked 


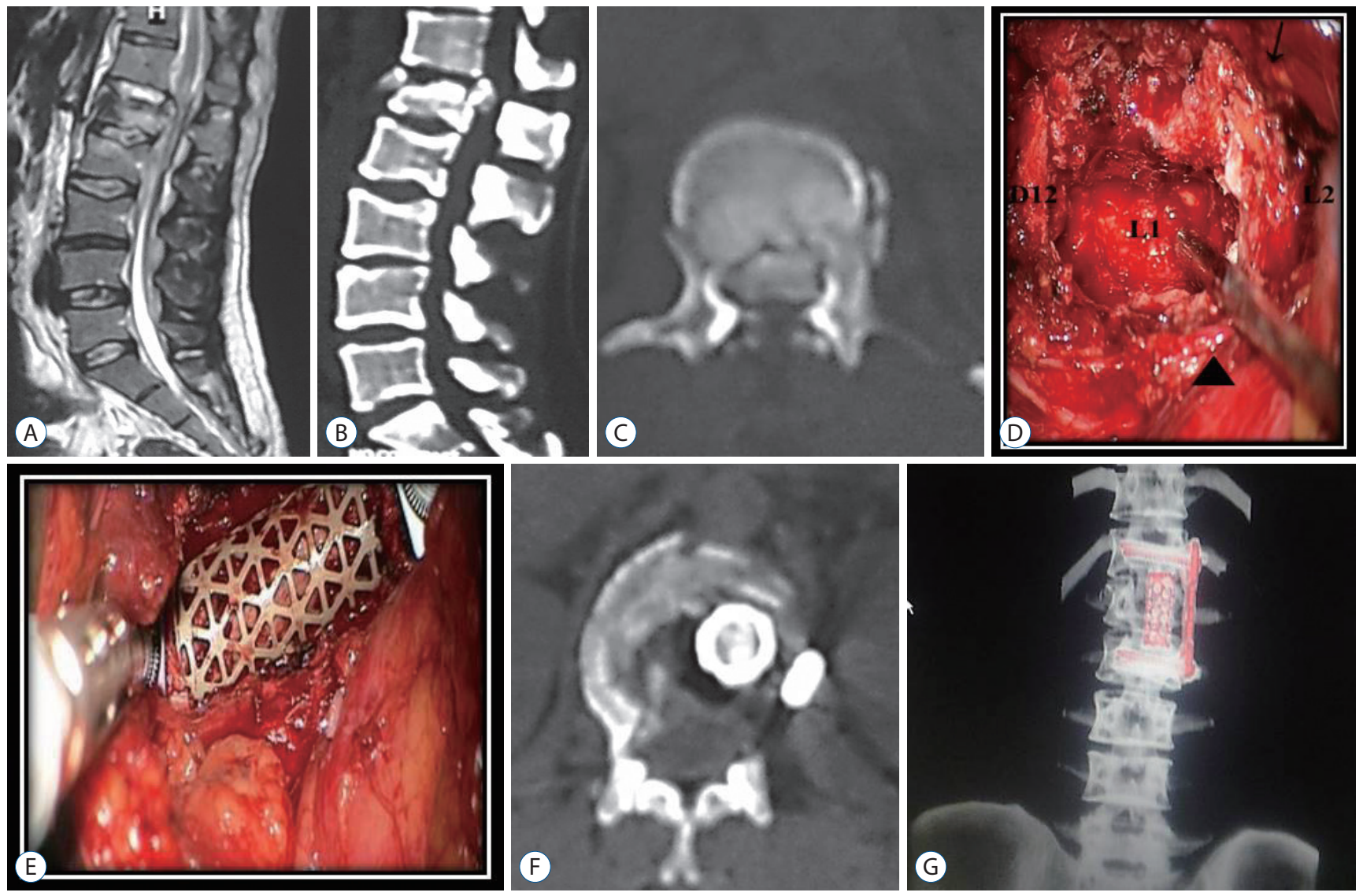

Fig. 2. A : Magnetic resonance imaging (sagittal view) showing a traumatic L1 fracture. B and C : CT scan (sagittal and axial views) of the same patient showing spinal canal compression with a large bony fragment compromising the spinal canal. D: Intraoperative view after retraction of the peritoneum anteriorly (arrowhead) and the psoas muscle posteriorly (arrow) showing the cavity created after corpectomy. E : Intraoperative view showing the insertion of titanium mesh filled with bone into the corpectomy site. F : CT scan (axial view) showing satisfactory spinal canal decompression. G : Postoperative follow-up CT scan with 3D reconstruction (AP view) showing the L1 corpectomy with reconstruction using titanium mesh and spinal instrumentation using an anterolateral plate extending from D12 to L2. CT : computed tomography, AP : anteroposterior.

improvement. One patient developed neurological deterioration on the 5th postoperative day due to bone graft dislodgement. This patient required a second surgery to reposition the graft and improved over the following 2 months.

\section{Outcomes}

No operative mortalities or vascular injuries occurred in this series. Significant improvement of back pain and radicular pain was recorded in the present study $(p<0.001)$. The preoperative low back pain VAS mean value dropped from 7.6 to 1.4 at last follow up and the preoperative radicular pain VAS mean value dropped from 6.8 to 0.8 (Table 2).

All patients with pre-operative deficits (67\%) exhibited improvement on the ASIA impairment scale during the followup period; 12 patients improved from grade $\mathrm{D}$ to grade $\mathrm{E}$, four patients improved from grade $\mathrm{C}$ to grade $\mathrm{D}$, two patients improved from grade $\mathrm{B}$ to grade $\mathrm{C}$, and two patients improved from grade $\mathrm{C}$ to grade $\mathrm{E}$ (Figs. 4 and 5) during the follow-up period. No hardware failures or losses of correction were detected. The mean preoperative Cobb angle was $20.6^{\circ}$ (range, $3-37^{\circ}$ ) improved to $9.8^{\circ}$ (range, $2-22^{\circ}$ ) at last follow up which was proven to be significant.

Fusion was achieved in 16 of the 18 patients with bone grafts (90\%), and in the remaining 12 cases, bone cement was used for reconstruction.

\section{DISCUSSION}

The L1 vertebra is a part of the thoracolumbar junction, 

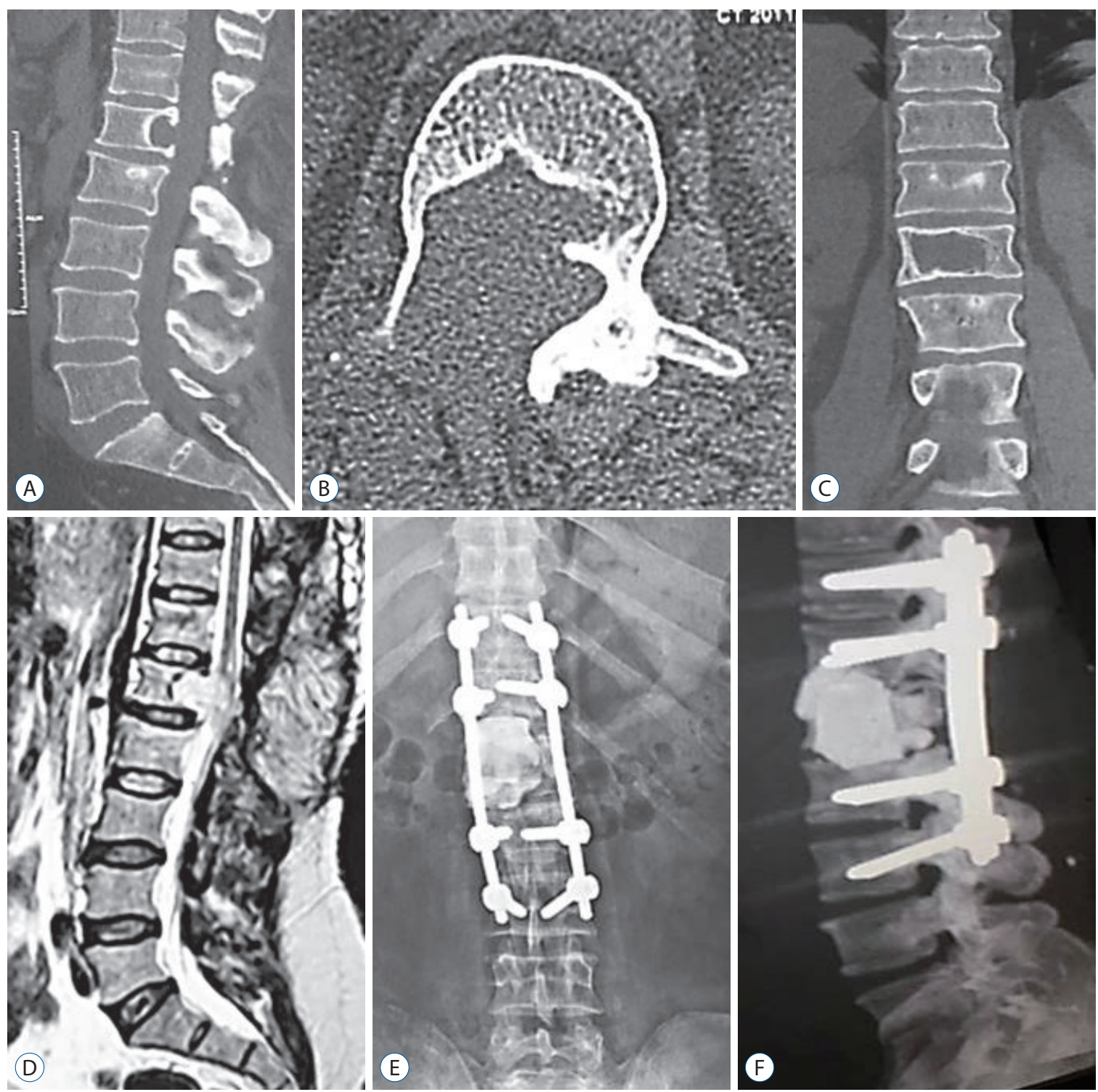

Fig. 3. A-C : CT scan (sagittal, axial and coronal views) showing an L1 osteolytic lesion in a patient with a previous posterior spinal surgery. D : Magnetic resonance imaging (sagittal view) showing the L1 neoplastic lesion compromising the spinal canal. E : Plain X-ray (AP views) showing evidence of L1 corpectomy with reconstruction using bone cement together with spinal instrumentation using transpedicular screws two levels above and two levels below the lesion, which was diagnosed as hemangioma. F : CT scan with 3D reconstruction (lateral view) of the same patient. CT : computed tomography, AP : anteroposterior.

Table 2. Comparison between the preoperative and last follow-up postoperative VAS for LBP and radicular pain

\begin{tabular}{lcccc} 
& \multicolumn{3}{c}{ VAS } \\
\cline { 2 - 5 } & Preoperative LBP & Preoperative radicular pain & Postoperative LBP & Postoperative radicular pain \\
\hline Range & $7.35-8.45$ & $6.35-8.66$ & $0.91-1.59$ & $0.65-1.1$ \\
Mean & 7.6 & 6.8 & 1.4 & 0.8 \\
$p$-value* & & $<0.001^{\dagger}$ & $<0.001^{\dagger}$ \\
\hline
\end{tabular}

*Wilcoxon signed ranks test for comparing between preoperative and each other periods. 'Statistically significant at $p \leq 0.05$. VAS : visual analogue scale, LBP : low back pain 


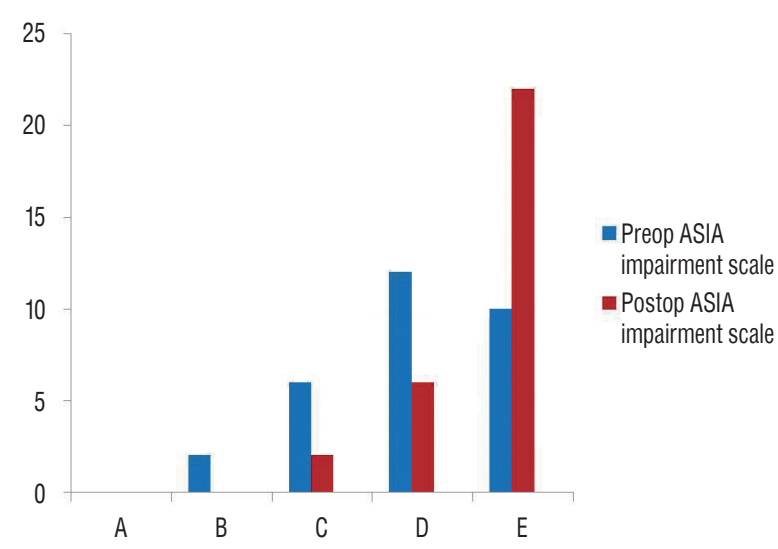

Fig. 4. ASIA impairment scale of all patients both pre- and post-operatively.

which is among the most intricate areas of the vertebral column and among the sites that are most liable to injury. L1 corpectomies can be performed using dorsal or ventral approaches. Posterior transpedicular corpectomy, which can be performed unilaterally or bilaterally, cannot typically guarantee adequate decompression due to the limited direct visualization of the spinal canal. In contrast, anterior corpectomy allows for more direct and complete vertebral resection with a minimal risk of neural injury considering that it involves the conus medullaris. This approach also allows for the restoration of vertebral alignment, the correction and prevention of kyphotic deformities, and rigid fixation to promote fusion ${ }^{4,5)}$.

Different anterior approaches to the dorsal and lumbar spine have been described in recent decades, and these approaches are continuously modified to decrease trauma and increase feasibility ${ }^{4,5,11,13)}$. The conventional transthoracic transpleural transdiaphragmatic approach is currently considered extremely invasive by many surgeons because this approach requires a larger cut into the diaphragm, and the violation of the thoracic cavity is associated with possible serious complications such as pneumonia, pleural effusion, hemothorax, pneumothorax atelectasis, incomplete lung expansion and respiratory insufficiency. Furthermore, tuberculous infection could spread from the lungs to the spine ${ }^{15,45)}$.

The retroperitoneal extrapleural approach is generally less invasive and can be performed through the 11th or 12th rib; however, using this approach, it is usually more difficult to preserve the integrity of the pleural cavity, thereby increasing the likelihood of chest complications ${ }^{17}$. In our experience, the retroperitoneal extrapleural approach through the 12th rib offered adequate exposure for the performance of L1 corpecto-

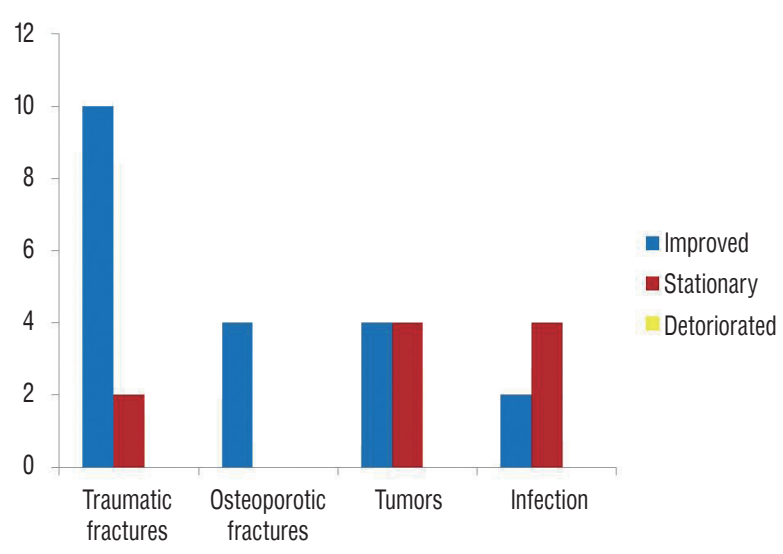

Fig. 5. Outcome of patients with regard to the etiology.

my in all cases with only a limited disinsertion of the diaphragm from its vertebral attachment that did not involve cutting the diaphragm, consequently decreasing the incidence of pulmonary complications and eliminating the need for postoperative chest tube insertion. Also, the rate of abdominal distention and reflex ileus is very minimal with the present approach due to avoidance of T11, T12 intercostal nerve injury and no violation to the peritoneum ${ }^{14,24)}$.

Similar to many other reports, we successfully used this approach to manage fractures, infections and tumors $9,18,20,21,23,34,41,46)$. This approach can also be used to manage spinal deformities because it allows the surgeon to perform an anterior release and increases the surface area for healing and/or instrumenting the spine ${ }^{46)}$. In a series of 80 patients who underwent surgeries for various thoracolumbar pathologies (i.e., fractures, infections and tumors), Lu and colleagues ${ }^{25)}$ compared the results of posterior transpedicular corpectomy with those of anterior corpectomy. These authors found that single-level transpedicular corpectomy was comparable to anterior-only corpectomy in terms of estimated blood loss and operative time. In the present series, the mean operative time was 220 minutes (range, 160-280), and the mean blood loss volume was $600 \mathrm{~mL}$ (range, 400-1400). Payer and Sottas ${ }^{34)}$ reported similar results; their mean operative time was 191 minutes (range, 120-253), and the mean blood loss was $670 \mathrm{~mL}$ (range, 350-2000). We noticed decreasing patterns in both blood loss and operative time in the most recent cases. Similarly, in a series reported by Lin et al. ${ }^{23)}$, the operation time decreased from 152 minutes (67-285) in the first year to 85 minutes (62-124) over the next 6 years, and the mean blood loss also exhibited a decrease from $425 \mathrm{~mL}(200-1150)$ in the first year to $136 \mathrm{~mL}$ 
(minimal-250) over the next 6 years.

Various complications associated with anterior approaches to the thoracolumbar spine have been reported and range from wound infection and painful scars to severe chest complications, peritonitis, retroperitoneal fibrosis and serious visceral and neurovascular injuries $3,12,23,26,28,30,31,45,48)$. The reported morbidities in the present series were generally minor and manageable without any grave sequelae. The complication rate associated with anterior-only corpectomy is comparable to that associated with posterior transpedicular corpectomy ${ }^{25,37)}$.

In our opinion, one of the advantages of the retroperitoneal extrapleural approach is the ability to adequately reconstruct the vertebra and apply additional ventral instrumentation in the same session, thus avoiding a second surgical procedure. Combined anterior corpectomy and posterior fixation has been found to be associated with higher complication rates regardless of whether the procedures are performed in one or two sessions. Patients undergoing combined approaches are more likely to exhibit wound infections, scar healing problems, and nutritional, respiratory and blood loss complications $^{23,25,35,38,42)}$. Due to the direct ventral exposure using the retroperitoneal extrapleural approach, spinal canal decompression can be more effectively accomplished along with kyphosis correction and reconstruction of the weight-bearing anterior column, which carries most of the axial physiological load. Our study demonstrated reliable neurological improvements of at least one ASIA impairment grade on final observation in all patients with pre-operative deficits. These improvements could be achieved while preserving back muscle functions and avoiding excessive nerve retraction and subsequent perineural adhesions ${ }^{19,22,36,40)}$. Arguments in favor of a purely posterior transpedicular procedure include the fact that it is a commonly used approach that involves less invasive access and excellent spinal canal decompression, and the anterior column can also be reached through the pedicle. However, this technique is associated with a considerable loss of correction, and the aim of anterior fusion cannot be reliably achieved $^{6,19,25,37)}$. Anterior spinal fusion provides a biomechanically superior construct with greater physiological support and enhances the incorporation of bone grafts to host bone, which leads to higher fusion rates. These findings are consistent with our results because none of our patients experienced hardware failure, and fusion was achieved in $90 \%$ of the cases with bone grafts. Although several biomechanical studies have stated that the highest achievable stability is provided by combined anterior and posterior fixation, several authors have reported excellent fusion rates using the anterior-only approach that are comparable to those achieved using combined anterior and posterior fixation ${ }^{19,22,23,34,40,47)}$.

Minimally invasive anterior approaches via laparoscopic or video-assisted thoracoscopic techniques have been well-described in the literature ${ }^{1,7,8,16,44)}$. These approaches to the anterior thoracolumbar spine have advantages, such as shorter hospitalization, shorter recovery time, and better cosmetic results, over open approaches ${ }^{7,27)}$. However, several authors have reported a higher incidence of complications using endoscopic approaches $^{12)}$. Moreover, open anterior approaches are easier to learn, less expensive, and offer direct vision and a more hands-on approach. The associated incision and tissue morbidity, recovery time, and length of hospital stay appear to be reduced with cumulative experience and the use of smaller incisions. Indeed, the mini-open anterior thoracolumbar approach through the 12 th rib can be considered a safe, reliable, and cost-effective alternative to endoscopic approaches that elicits comparable results in terms of operative time, blood loss and length of hospital stay ${ }^{4,11,23,34)}$.

\section{CONCLUSION}

The anterior retroperitoneal extrapleural approach through the 12th rib is a feasible approach for the performance of L1 corpectomy for different pathologies involving the L1 vertebra. This approach allows for satisfactory decompression of the neural elements and effective reconstruction of the loadbearing capacity of the thoracolumbar junction. It is cost-effective and safe with minimal morbidity and can usually be performed without violating the chest cavity and with limited manipulation of the diaphragm. It is associated with less pulmonary complication, no need for chest tube, no abdominal distention and rapid recovery compared with other approaches. This approach also allows for anterior instrumentation in the same stage with high fusion rates without the need to posteriorly augment the fusion in most cases. 


\section{CONFLICTS OF INTEREST}

No potential conflict of interest relevant to this article was reported.

\section{INFORMED CONSENT}

Informed consent was obtained from all individual participants included in this study.

\section{- Acknowledgements}

This study was presented at the 83rd AANS annual scientific meeting in Washington, DC, USA (May 2 to 6, 2015).

The authors would like to acknowledge the staff of departments of neurosurgery, neuroradiology and physiotherapy for their support.

\section{References}

1. Anand N, Regan JJ : Video-assisted thoracoscopic surgery for thoracic disc disease: classification and outcome study of 100 consecutive cases with a 2-year minimum follow-up period. Spine (Phila Pa 1976) 27 : 871-879, 2002

2. Anderson TM, Mansour KA, Miller JI Jr : Thoracic approaches to anterior spinal operations: anterior thoracic approaches. Ann Thorac Surg 55 : 1447-1451, 1993

3. Baker JK, Reardon PR, Reardon MJ, Heggeness MH : Vascular injury in anterior lumbar surgery. Spine (Phila Pa 1976) 18 : 2227-2230, 1993

4. Beisse $R$ : Endoscopic surgery on the thoracolumbar junction of the spine. Eur Spine J 19 Suppl 1 : S52-S65, 2010

5. Bradford DS, McBride GG : Surgical management of thoracolumbar spine fractures with incomplete neurologic deficits. Clin Orthop Relat Res (218) : 201-216, 1987

6. Chou D, Wang VY, Gupta N : Transpedicular corpectomy with posterior expandable cage placement for L1 burst fracture. J Clin Neurosci 16 : 1069-1072, 2009

7. Cunningham BW, Kotani Y, McNulty PS, Cappuccino A, Kanayama M, Fedder IL, et al. : Video-assisted thoracoscopic surgery versus open thoracotomy for anterior thoracic spinal fusion. a comparative radiographic biomechanical, and histologic analysis in a sheep model. Spine (Phila Pa 1976) 23 : 1333-1340, 1998

8. Escobar E, Transfeldt E, Garvey T, Ogilvie J, Graber J, Schultz L : Videoassisted versus open anterior lumbar spine fusion surgery: a comparison of four techniques and complications in 135 patients. Spine (Phila Pa 1976) $28: 729-732,2003$
9. Faciszewski $T$, Winter RB, Lonstein JE, Denis F, Johnson $L$ : The surgical and medical perioperative complications of anterior spinal fusion surgery in the thoracic and lumbar spine in adults. a review of 1223 procedures. Spine (Phila Pa 1976) 20 : 1592-1599, 1995

10. Fourney DR, Gokaslan ZL : Anterior approaches for thoracolumbar metastatic spine tumors. Neurosurg Clin N Am 15 : 443-451, 2004

11. Gandhoke GS, Tempel ZJ, Bonfield CM, Madhok R, Okonkwo DO, Kanter AS : Technical nuances of the minimally invasive extreme lateral approach to treat thoracolumbar burst fractures. Eur Spine J 24 Suppl 3 : 353-360, 2015

12. Gumbs AA, Bloom ND, Bitan FD, Hanan SH : Open anterior approaches for lumbar spine procedures. Am J Surg 194 : 98-102, 2007

13. Hodgson AR, Yau AC : Anterior surgical approaches to the spinal column in Apley AG (ed): Recent Advances in Orthopedics. Williams \& Wilkins : Baltimore, 1964, pp289-323

14. Ikard RW : Methods and complications of anterior exposure of the thoracic and lumbar spine. Arch Surg 141 : 1025-1034, 2006

15. Jain AK, Dhammi IK, Jain S, Kumar J : Simultaneously anterior decompression and posterior instrumentation by extrapleural retroperitoneal approach in thoracolumbar lesions. Indian J Orthop 44 : 409-416, 2010

16. Kim DH, Jaikumar $\mathrm{S}$, Kam AC : Minimally invasive spine instrumentation. Neurosurgery 51(5 Suppl) : S15-S25, 2002

17. Kim M, Nolan P, Finkelstein JA : Evaluation of 11th rib extrapleuralretroperitoneal approach to the thoracolumbar junction. Technical note.

J Neurosurg 93(1 Suppl) : 168-174, 2000

18. Knoeller SM, Huwert $\mathrm{O}$, Wolter $\mathrm{T}$ : Single stage corpectomy and instrumentation in the treatment of pathological fractures in the lumbar spine. Int Orthop 36 : 111-117, 2012

19. Knop C, Lange $U$, Bastian $L$, Blauth $M$ : Three-dimensional motion analysis with Synex. Comparative biomechanical test series with a new vertebral body replacement for the thoracolumbar spine. Eur Spine J 9 : 472-485, 2000

20. Korkusuz F, Islam C, Korkusuz Z : Prevention of postoperative late kyphosis in Pott's disease by anterior decompression and intervertebral grafting. World J Surg 21 : 524-528, 1997

21. Korkusuz Z, Binnet MS, Isiklar ZU : Pott's disease and extrapleural anterior decompression. Results of 108 consecutive cases. Arch Orthop Trauma Surg 108 : 349-352, 1989

22. Kozak JA, O'Brien JP : Simultaneous combined anterior and posterior fusion. An independent analysis of a treatment for the disabled low-back pain patient. Spine (Phila Pa 1976) 15 : 322-328, 1990

23. Lin RM, Huang KY, Lai KA : Mini-open anterior spine surgery for anterior lumbar diseases. Eur Spine J 17 : 691-697, 2008

24. Litré CF, Duntze J, Benhima Y, Eap C, Malikov S, Pech-Gourg G, et al. : Anterior minimally invasive extrapleural retroperitoneal approach to the thoraco-lumbar junction of the spine. Orthop Traumatol Surg Res 99 : 94-98, 2013

25. Lu DC, Lau D, Lee JG, Chou D : The transpedicular approach compared with the anterior approach: an analysis of 80 thoracolumbar corpectomies. J Neurosurg Spine 12 : 583-591, 2010 
26. McAfee PC : Complications of anterior approaches to the thoracolumbar spine. Emphasis on Kaneda instrumentation. Clin Orthop Relat Res 306 : 110-119, 1994

27. McAfee PC, Regan JR, Zdeblick T, Zuckerman J, Picetti GD 3rd, Heim S, et al. : The incidence of complications in endoscopic anterior thoracolumbar spinal reconstructive surgery. A prospective multicenter study comprising the first 100 consecutive cases. Spine (Phila Pa 1976) 20 : 1624-1632, 1995

28. McDonnell MF, Glassman SD, Dimar JR 2nd, Puno RM, Johnson JR : Perioperative complications of anterior procedures on the spine. J Bone Joint Surg Am 78 : 839-847, 1996

29. McDonough PW, Davis R, Tribus C, Zdeblick TA : The management of acute thoracolumbar burst fractures with anterior corpectomy and Zplate fixation. Spine (Phila Pa 1976) 29 : 1901-1908; discussion 1909, 2004

30. Orchowski J, Bridwell KH, Lenke LG : Neurological deficit from a purely vascular etiology after unilateral vessel ligation during anterior thoracolumbar fusion of the spine. Spine (Phila Pa 1976) 30 : 406-410, 2005

31. Oskouian RJ Jr, Johnson JP : Vascular complications in anterior thoracolumbar spinal reconstruction. J Neurosurg 96(1 Suppl) : 1-5, 2002

32. Oskouian RJ Jr, Shaffrey Cl, Whitehill R, Sansur CA, Pouratian N, Kanter AS, et al. : Anterior stabilization of three-column thoracolumbar spinal trauma. J Neurosurg Spine 5 : 18-25, 2006

33. Pappou IP, Papadopoulos EC, Swanson AN, Mermer MJ, Fantini GA, Urban MK, et al. : Pott disease in the thoracolumbar spine with marked kyphosis and progressive paraplegia necessitating posterior vertebral column resection and anterior reconstruction with a cage. Spine (Phila Pa 1976) 31 : E123-E127, 2006

34. Payer $\mathrm{M}$, Sottas $\mathrm{C}$ : Mini-open anterior approach for corpectomy in the thoracolumbar spine. Surg Neurol 69 : 25-31; discussion 31-32, 2008

35. Penta M, Fraser RD : Anterior lumbar interbody fusion. a minimum 10year follow-up. Spine (Phila Pa 1976) 22 : 2429-2434, 1997

36. Pflugmacher R, Schleicher P, Schaefer J, Scholz M, Ludwig K, Khodadadyan-Klostermann $C$, et al. : Biomechanical comparison of expandable cages for vertebral body replacement in the thoracolumbar spine. Spine (Phila Pa 1976) 29 : 1413-1419, 2004

37. Pham MH, Tuchman A, Chen TC, Acosta FL, Hsieh PC, Liu JC : Transpedicular corpectomy and cage placement in the treatment of traumatic lumbar burst fractures. Clin Spine Surg 30 : 360-366, 2017
38. Pradhan BB, Nassar JA, Delamarter RB, Wang JC : Single-level lumbar spine fusion: a comparison of anterior and posterior approaches. J Spinal Disord Tech 15 : 355-361, 2002

39. Quint $U$, Wilke HJ, Löer F, Claes LE : Functional sequelae of surgical decompression of the lumbar spine--a biomechanical study in vitro. $\mathbf{Z}$ Orthop Ihre Grenzgeb $136:$ 350-357, 1998

40. Rauzzino MJ, Shaffrey Cl, Nockels RP, Wiggins GC, Rock J, Wagner J : Anterior lumbar fusion with titanium threaded and mesh interbody cages. Neurosurg Focus 7 : e7, 1999

41. Reinhold M, Knop C, Beisse R, Audigé L, Kandziora F, Pizanis A, et al. : Operative treatment of 733 patients with acute thoracolumbar spinal injuries: comprehensive results from the second, prospective, internetbased multicenter study of the Spine Study Group of the German Association of Trauma Surgery. Eur Spine J 19 : 1657-1676, 2010

42. Saraph V, Lerch C, Walochnik N, Bach CM, Krismer M, Wimmer C : Comparison of conventional versus minimally invasive extraperitoneal approach for anterior lumbar interbody fusion. Eur Spine J 13 : 425431, 2004

43. Sasso RC, Renkens K, Hanson D, Reilly T, McGuire RA Jr, Best NM : Unstable thoracolumbar burst fractures: anterior-only versus short-segment posterior fixation. J Spinal Disord Tech 19 : 242-248, 2006

44. Scheufler KM : Technique and clinical results of minimally invasive reconstruction and stabilization of the thoracic and thoracolumbar spine with expandable cages and ventrolateral plate fixation. Neurosurgery 61 : 798-808; discussion 808-809, 2007

45. Schnake KJ, Stavridis SI, Kandziora F : Five-year clinical and radiological results of combined anteroposterior stabilization of thoracolumbar fractures. J Neurosurg Spine $20:$ 497-504, 2014

46. Tribus $C$ : Anterior approach to the thoracic and thoracolumbar spine. Semin Spine Surg $21:$ 49-54, 2009

47. Wilke HJ, Kemmerich V, Claes LE, Arand M : Combined anteroposterior spinal fixation provides superior stabilisation to a single anterior or posterior procedure. J Bone Joint Surg Br 83 : 609-617, 2001

48. Winter RB, Lonstein JE, Denis F, Leonard AS, Garamella JJ : Paraplegia resulting from vessel ligation. Spine (Phila Pa 1976) 21 : 1232-1234, 1996

49. Zdeblick TA, David SM : A prospective comparison of surgical approach for anterior L4-L5 fusion: laparoscopic versus mini anterior lumbar interbody fusion. Spine (Phila Pa 1976) 25 : 2682-2687, 2000 